\title{
MARCEL SCHWOB, Vite immaginarie
}

\section{Mario Richter}

\section{OpenEdition \\ Journals}

\section{Edizione digitale}

URL: https://journals.openedition.org/studifrancesi/45385

DOI: $10.4000 /$ studifrancesi.45385

ISSN: 2427-5856

\section{Editore}

Rosenberg \& Sellier

\section{Edizione cartacea}

Data di pubblicazione: 1 août 2021

Paginazione: 397

ISSN: 0039-2944

\section{Notizia bibliografica digitale}

Mario Richter, «MARcel Sснwoв, Vite immaginarie», Studi Francesi [Online], 194 (LXV | II) | 2021, online dal 01 septembre 2021, consultato il 14 octobre 2022. URL: http://journals.openedition.org/studifrancesi/ 45385 ; DOI: https://doi.org/10.4000/studifrancesi.45385

Questo documento è stato generato automaticamente il 14 octobre 2022.

\section{(c)}

Creative Commons - Attribuzione - Non commerciale - Non opere derivate 4.0 Internazionale - CC BYNC-ND 4.0

https://creativecommons.org/licenses/by-nc-nd/4.0/ 


\title{
MARCEL SCHWOB, Vite immaginarie
}

\author{
Mario Richter
}

\section{NOTIZIA}

MARCEL SCHWOB, Vite immaginarie, a cura di L. Salvatore. Con un saggio di R. Castellana, Milano, Feltrinelli, 2020, 298 pp.

Già più volte e variamente tradotte fin dal 1946 (da Irene Brin, Maria Teresa Escoffier, Fleur Jaeggy, Nicola Muschitiello, Austin O. e Cristina Lando), Les Vies imaginaires sono state nuovamente messe a disposizione del pubblico italiano nella traduzione di Luca SALVATORE, lo studioso che in quest'ultimo decennio si è distinto per aver felicemente trasferito nella lingua italiana opere francesi di particolare impegno come Les Chants de Maldoror, Les Amours jaunes e L'Assommoir. Nella Prefazione il curatore mette bene in luce il contesto e soprattutto la specificità dell'opera, rilevandone il distacco dai criteri "scientifici" dell'allora ancor vivo Naturalismo. «La vita corre più in fretta del Realismo - osserva l'A. - l'immaginazione precede sempre la Vita: ecco perché le Vies imaginaires o i romanzi di Stevenson, narrando cose belle non vere, mentendo sapendo di mentire, sono più 'vivi' di qualsiasi ritratto del Secondo Impero» (p. 13). Quanto al carattere della particolare scrittura di Schwob, l'impegno e l'attenzione che ogni traduzione richiede porta Salvatore a rilievi di particolare interesse, come quando scrive che «l'intrico quasi impossibile da strigare di cripto-citazioni ed ecolalie, il sovrapporsi dei riferimenti, il mutamento continuo nel contiguo, nel successivo, nell'opposto, si traducono mirabilmente, e come mai era stato fatto prima, in sapiente ventriloquio e ogni tentativo di ricostruire, come le tessere musive di un mosaico, una qualsiasi vita [...] mette sulle tracce di un'assenza, di un malevolo destino» (p. 19). Le già ricche pagine di Salvatore trovano, alla fine del libro, un'ulteriore nutritiva estensione storico-critica in un saggio di Riccardo CASTELLANA, che persuasivamente illustra l'influenza e gli sviluppi che ha avuto il libro di Schwob nella cultura novecentesca anche italiana, concludendo che «abbandonato il mito dell'esteta demiurgo caro a Schwob (e a d'Annunzio), la finzione biografica ha però conservato, del progetto 
originario delle Vies, il diritto all'invenzione: non più demiurgo del piccolo mondo del Bello, lo scrittore di vite immaginarie conserva oggi, tuttavia, il privilegio di raccontare storie e, così facendo, di farci sognare altre vite» (p. 235). Il libro si conclude con una esaustiva informazione bio-bibliografica. 